16 Department of Health. Government Response to Professor Sube Banerjee's Report on the Prescribing of Anti-Psychotic Drugs To People With Dementia. Department of Health, 2009.

17 Haw C, Yorston G, Stubbs J. Guidelines on antipsychotics for dementia: are we losing our minds? Psychiatr Bull 2009; 33: 57-60.

18 Sutherland R. Government commits to reducing antipsychotics for people with dementia by two thirds in a year. Alzheimer's Society, 2010.

19 Treloar A, Crugel M, Prasanna A, Solomons L, Fox C, Paton C, et al. Ethical dilemmas: should antipsychotics ever be prescribed for people with dementia? Br J Psychiatry 2010; 197: 88-90.

20 Wittmann M, Hausner H, Hajak G, Haen E. Antipsychotic treatment of dementia after publication of new risks [in German]. Psychiatr Prax 2010; 37: 68-70.

21 Shah A. Can risperidone and olanzapine in elderly patients with dementia and other mental disorders be discontinued? Int J Geriatr Psychiatry 2006; 21: 140-6.
22 Barnes TRE, Paton C. Antipsychotic polypharmacy in schizophrenia: benefits and risks. CNS Drugs 2011; 25: 383-99.

23 Zahodne LB, Fernandez HH. Pathophysiology and treatment of psychosis in Parkinson's disease: a review. Drugs Aging 2008; 25: 665-82.

24 Ballard C, Waite J. The effectiveness of atypical antipsychotics for the treatment of aggression and psychosis in Alzheimer's disease. Cochrane Database Syst Rev 2006; 1: CD003476.

25 Gibbons RD, Hur K, Bhaumik DK, Mann JJ. The relationship between antidepressant prescription rates and rate of early adolescent suicide. Am J Psychiatry 2006; 163: 1898-904.

26 Department of Health. Commissioning pack resources: reduce inappropriate prescribing of antipsychotics. Department of Health, 2012.

\title{
Perception of unmet needs and association with benzodiazepine misuse among patients on a methadone maintenance treatment programme
}

\author{
Tunde Apantaku-Olajide, ${ }^{1}$ Kevin Ducray, ${ }^{2}$ Patricia Byrne, ${ }^{2,3}$ Bobby P. Smyth ${ }^{2,4}$
}

The Psychiatrist (2012), 36, 169-174, doi: 10.1192/pb.bp.111.036616

\begin{abstract}
Department of Psychiatry, Dalhousie University, Canada; ${ }^{2}$ Drug Treatment Centre Board, Dublin, Ireland; ${ }^{3}$ Linn Dara Child and Adolescent Mental Health Service, Dublin, Ireland ${ }^{4}$ Department of Public Health and Primary Care, Trinity College Dublin Ireland

Correspondence to Tunde Apantaku-Olajide

(tunde.apantaku-olajide@gnb.ca)

First received 27 Aug 2011, final revision 4 Nov 2011, accepted 2 Dec 2011
\end{abstract}

Aims and method To examine patients' perceptions of unmet needs during methadone maintenance treatment (MMT), and to explore the relationship between co-occurring benzodiazepine misuse and severity of needs. A cross-sectional survey was carried out at an MMT programme in Dublin, Ireland. All patients were invited to participate on a voluntary basis. Of the 191 eligible patients, 107 agreed to participate and completed the Camberwell Assessment of Need questionnaire.

Results Unmet needs for substance misuse treatments, daytime activities, socialisation, money management and psychological distress were high. Fifty-two respondents (49\%) reported using non-prescribed benzodiazepines during the past month. Compared with non-users of benzodiazepines, benzodiazepine users reported higher ratings of total and unmet needs $(P<0.05)$. The number of days using benzodiazepines predicted the severity of needs.

Clinical implications The findings highlight the importance of addressing coexisting psychological needs, and further support enhancing treatment interventions for benzodiazepine misuse or dependence among patients on MMT.

Declaration of interest None.
Research shows that actively assessing and addressing patient-rated unmet needs is a useful starting point for healthcare delivery. ${ }^{1,2}$ The Camberwell Assessment of Need (CAN) questionnaire is the most widely used needsassessment tool. ${ }^{3}$ We searched the PubMed, PsycINFO and PsycARTICLES databases for publications on CAN using the following terms: addiction, drug dependence, heroin AND methadone; the search yielded only four studies, conducted primarily in mental healthcare systems. ${ }^{4-7}$ Nevertheless, surveys using non-standardised assessments have found high levels of unmet needs, particularly legal, basic, financial, family, social services, medical and mental healthcare, in addiction patient groups. ${ }^{8-11}$ Unmet need is a predictor of perceived quality of care; therefore, enhancing patients' access to services that meet their additional needs promotes treatment engagement and outcomes. ${ }^{8-10,12}$ Most opioid-dependent individuals manifest ongoing polysubstance use, have related complex needs, and present major treatment challenges because no single treatment service is likely to meet all their needs. ${ }^{11,13}$ The levels of unmet need for specific ancillary services during intensive specialised care such as methadone maintenance treatment (MMT) programmes are unclear. ${ }^{8}$ 
Benzodiazepine use is a major public health problem. Lifetime use of benzodiazepines among opioid-dependent individuals is reported to be $66-100 \%$, with estimates of problematic benzodiazepine misuse or dependence in people on MMT being $18-50 \% .{ }^{14}$ Research indicates that benzodiazepine misuse or dependence is associated with complex needs and negatively influences MMT outcomes. ${ }^{15-19}$ There are many reasons why patients on MMT use benzodiazepines. Benzodiazepine misuse may signify a desire for drug experience no longer achieved by opioids due to greater tolerance and methadone-induced narcotic blockade. ${ }^{19}$ Benzodiazepine misuse may also represent an attempt to negate the increasing tolerance to opioids by accessing other drugs that provide alternative rewarding effects. ${ }^{19,20}$ Compared with patients on MMT who do not use benzodiazepines, patients on MMT who use benzodiazepines manifest higher levels of polysubstance use (heroin, cocaine), higher levels of psychopathology (including depression and anxiety), poorer social functioning (including unemployment and criminal activity), higher levels of injecting practices that carry a blood-borne virus risk, and greater overdose history. In addition, patients on MMT who use benzodiazepines often receive higher methadone doses than those who do not use benzodiazepines. ${ }^{14-19}$

In addition to morbidity, benzodiazepine misuse and dependence is implicated in $20-80 \%$ of methadone-related deaths. $^{14}$

In this study, we examined MMT patients' perceptions of unmet needs for comprehensive treatment care and explored the relationship between benzodiazepine misuse and severity of need. Our hypothesis was that use of nonprescribed benzodiazepines would be associated with a higher severity of unmet needs.

\section{Method}

The Research Ethics Committee of the Drug Treatment Centre Board in Dublin approved the study. This is the oldest, largest addiction treatment centre in Ireland, providing a broad range of out-patient treatments, including specialist psychiatric, psychological, social and medical interventions. Only service users who were opioiddependent and who had received MMT for at least 3 months were eligible for inclusion in the survey. Service users with acute or end-stage medical problems (e.g. AIDS) were excluded. To maximise participation, all eligible service users were sent a personal letter explaining the study and inviting them to participate. Service users who did not respond to this letter were approached personally and verbally invited to participate.

Sociodemographic data and information on substances used in the 30 days preceding the study were obtained using the appropriate section of the Maudsley Addiction Profile. Each respondent completed the Camberwell Assessment of Need Short Appraisal Schedule, patient-rated version (CANSAS-P). This tool was chosen because of its good psychometric properties. The CANSAS-P exhibits comparable detection of needs with the Camberwell Assessment of Need Short Appraisal Schedule (CANSAS), good reliability and validity, especially for unmet needs. The CANSAS-P is better at identifying the needs that patients are less likely to admit to on CANSAS, and is generally positively evaluated by patients. $^{21}$ Slade and colleagues asserted that patient ratings of need are more reliable than staff ratings. ${ }^{22}$ The CANSAS-P assesses need on 22 items. The rater indicates any perceived need and determines whether this need is being met $(0=$ no need; $1=$ not a serious problem because of help received, i.e. met need; $2=$ current serious problem despite help received, i.e. unmet need). The CANSAS-P provides scores on total needs, unmet needs and met needs; higher scores indicate higher severity of need. ${ }^{23}$ For the purpose of this study, only information about perceived need and whether it was met or unmet was used.

\section{Statistical analysis}

Descriptive data are presented as percentages and means. Comparisons were made between benzodiazepine users' and non-users' ratings of need. In the absence of any study using CANSAS in the opioid-dependent groups, we estimated that the mean unmet need would be 5 , based on studies in mental healthcare, and considered that a difference of 2 between benzodiazepine users and non-users would be clinically meaningful. ${ }^{24}$ With the expected standard deviation (s.d.) of 3.0, we required 102 participants to have $90 \%$ power to detect such difference, with a $P$-value of 0.05 . Categorical variables were analysed using the Pearson $\chi^{2}$ test for independence, and group differences for continuous variables were analysed using the independent $t$-test. Linear regression 'enter' method analysis was used to test the predictive ability of benzodiazepine misuse on the severity of needs, while controlling for polysubstance use in the multivariable analysis. All analyses were carried out using PASW version 18.0 (SPSS Inc, Chicago, Illinois, USA, 2009; www.spss.com).

\section{Results}

A total of 191 eligible patients were invited to participate in the study. Of these, 107 agreed to participate (response rate $56 \%)$. Non-responders either actively declined to participate $(n=43)$, failed to respond to verbal and written invitations to participate $(n=38)$, had time constraints preventing them meeting with the researchers $(n=1)$, died $(n=1)$ or were acutely psychiatrically unwell during the survey period $(n=1)$. No significant difference existed between the responders and the decliners with respect to the examined sociodemographic data.

The demographic and substance use characteristics of the respondents are presented in Table 1. Of the 107 respondents, $52(48.6 \%)$ reported using non-prescribed benzodiazepines in the 30 days preceding the study; 51 of these respondents (47.7\%) reported oral use only and 1 respondent $(0.9 \%)$ reported both oral and intravenous use. The days of reported use ranged from 1 to 30 days (mean $=13.8$, median $=9.5)$. Of the users of non-prescribed benzodiazepines, 47 (90.4\%) gave benzodiazepine-positive urine samples at routine urinalysis drug screens in the 30 days preceding the study. Users of non-prescribed benzodiazepines differed significantly from non-users in 


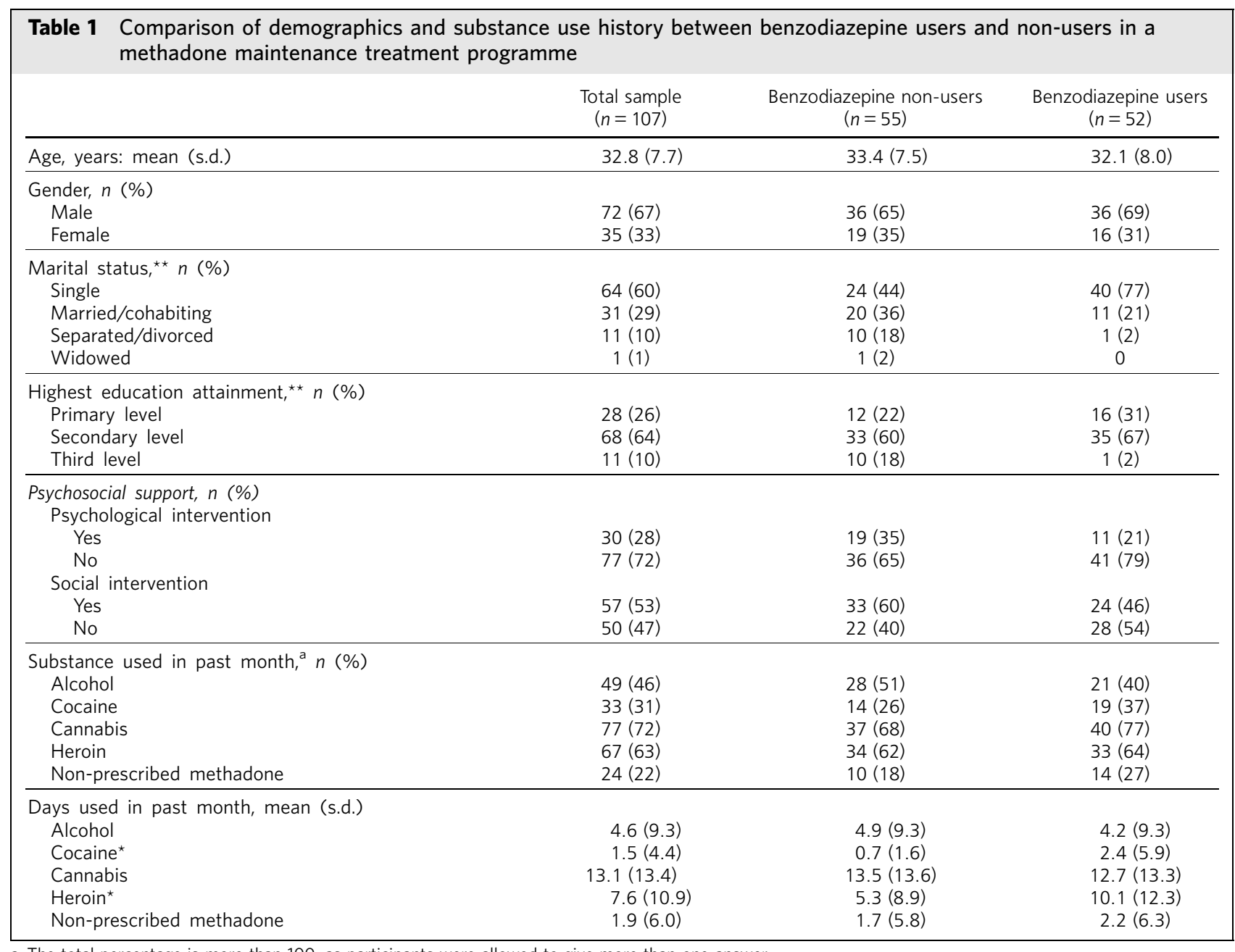

a. The total percentage is more than 100, as participants were allowed to give more than one answer

${ }^{\star} P<0.05$, independent $t$-test for continuous variables; ${ }^{\star \star} P<0.01, \chi^{2}$ test for categorical variables; .

terms of marital status, educational attainment, and extent of cocaine and heroin use in the past month (Table 1).

\section{CANSAS-P}

The proportions of perceived need, met need and unmet need for each CANSAS-P item are presented in Table 2. Among all the respondents, the mean number of total needs was 7.1 (s.d.=3.3), with 1.7 (s.d.=1.4) needs met and 5.4 (s.d. $=2.9)$ needs unmet.

The proportion of unmet needs exceeded that of met needs in 15 of the 22 items. The five items with the highest proportions of unmet need were drug use, psychological distress, daytime activities, social company, and physical health. The items with the fewest perceived needs were telephone access, self-care, looking after the home, and safety of others.

\section{Benzodiazepine use and perception of need}

The mean number of needs identified by users of benzodiazepines was 7.8 (s.d. $=3.1$ ), and the mean number of total needs identified by non-users was 6.4 (s.d. $=3.3$, $F=0.001$, d.f. $=105, P=0.02$ ). The mean number of met needs identified by users of benzodiazepines was 1.8 (s.d. $=1.4$, $F=0.007$, d.f. $=105, P=0.53$ ), and the mean number of met needs identified by non-users was 1.6 (s.d. =1.4). The mean number of unmet needs identified by users of benzodiazepines was 5.9 (s.d. $=2.8$ ), and the mean number of unmet needs identified by non-users was 4.7 (s.d. $=2$; $F=0.163$, d.f. $=105, P=0.02$ ). The areas in which these differences were statistically significant were drug use and daytime activities.

\section{Substances associated with severity of needs}

On univariate analysis, the mean number of days of reported use of heroin, non-prescribed methadone and cocaine was higher in the benzodiazepine-user group. These differences attained statistically significant levels for heroin and cocaine (Table 1). The effects of benzodiazepine use on total and unmet need scores after controlling for heroin and cocaine use in the multivariate linear regression analyses are presented in Table 3. In accordance with our hypothesis, we found that a higher number of days of benzodiazepine use is significantly associated with higher total and unmet need scores. 
Table 2 Prevalence of needs among patients on methadone maintenance treatment, comparing benzodiazepine users and non-users ${ }^{a}$

\begin{tabular}{|c|c|c|c|c|c|c|}
\hline \multirow{2}{*}{$\begin{array}{l}\text { Camberwell Assessment } \\
\text { of Need questionnaire } \\
\text { item }\end{array}$} & \multicolumn{3}{|c|}{ Met needs, $n(\%)$} & \multicolumn{3}{|c|}{ Unmet needs, $n(\%)$} \\
\hline & $\begin{array}{l}\text { Total sample } \\
\quad(n=107)\end{array}$ & $\begin{array}{c}\text { Benzodiazepine } \\
\text { non-users }(n=55)\end{array}$ & $\begin{array}{l}\text { Benzodiazepine } \\
\text { users }(n=52)\end{array}$ & $\begin{array}{c}\text { Total sample } \\
\quad(n=107)\end{array}$ & $\begin{array}{c}\text { Benzodiazepine } \\
\text { non-users }(n=55)\end{array}$ & $\begin{array}{c}\text { Benzodiazepine } \\
\text { users }(n=52)\end{array}$ \\
\hline Accommodation & $28(26)$ & $12(22)$ & $16(31)$ & $9(8)$ & $4(7)$ & $5(10)$ \\
\hline Food & $9(8)$ & $3(6)$ & $6(12)$ & $8(8)$ & $2(4)$ & $6(12)$ \\
\hline Looking after the home & $3(3)$ & $2(4)$ & $1(2)$ & $2(2)$ & 0 & $2(4)$ \\
\hline Self-care & $2(2)$ & $1(2)$ & $1(2)$ & $4(4)$ & $1(2)$ & $3(6)$ \\
\hline Daytime activities* & $5(5)$ & $1(2)$ & $4(8)$ & $62(58)$ & $27(49)$ & $35(67)$ \\
\hline Physical health & $22(21)$ & $8(15)$ & $14(27)$ & $39(36)$ & $24(44)$ & $15(29)$ \\
\hline Psychotic symptoms & $15(14)$ & $9(17)$ & $6(12)$ & $11(10)$ & $3(6)$ & $8(15)$ \\
\hline $\begin{array}{l}\text { Information on condition } \\
\text { and treatment }\end{array}$ & $20(19)$ & $10(18)$ & $10(19)$ & $8(8)$ & $5(9)$ & $3(6)$ \\
\hline Psychological distress & $20(19)$ & $14(26)$ & $6(12)$ & $49(46)$ & $23(42)$ & $49(46)$ \\
\hline Self-harm & $7(7)$ & $4(7)$ & $3(6)$ & $20(19)$ & $7(13)$ & $13(25)$ \\
\hline Safety to others & $3(3)$ & 0 & $3(6)$ & $10(9)$ & $5(9)$ & $5(10)$ \\
\hline Alcohol & $6(6)$ & $1(2)$ & $5(10)$ & $8(8)$ & $4(7)$ & $4(8)$ \\
\hline Illicit drugs ${ }^{\star \star}$ & $6(6)$ & $6(11)$ & 0 & $101(94)$ & $49(89)$ & $52(100)$ \\
\hline Social company & $1(1)$ & $1(2)$ & 0 & $62(58)$ & $28(51)$ & $34(65)$ \\
\hline Intimate relationships & $0(0)$ & 0 & 0 & $22(21)$ & $10(18)$ & $12(23)$ \\
\hline Sexual expression & $1(1)$ & $1(2)$ & 0 & $21(20)$ & $9(16)$ & $12(23)$ \\
\hline Childcare & $12(11)$ & $4(7)$ & $8(15)$ & $23(22)$ & $9(16)$ & $14(27)$ \\
\hline Basic education & $3(3)$ & $2(4)$ & $1(2)$ & $16(15)$ & $6(11)$ & $10(19)$ \\
\hline Telephone access & $0(0)$ & 0 & 0 & $0(0)$ & 0 & 0 \\
\hline Transport & $10(9)$ & $3(6)$ & $7(14)$ & $2(2)$ & $2(4)$ & 0 \\
\hline Money & $3(3)$ & $2(4)$ & $1(2)$ & $53(50)$ & $24(44)$ & $29(56)$ \\
\hline Benefits & $8(8)$ & $6(11)$ & $2(4)$ & $43(40)$ & $20(36)$ & $23(44)$ \\
\hline
\end{tabular}

a. The total percentage for each collumn exceeds 100 , as participants were allowed to indicate multiple areas of need.

${ }^{\star} P<0.05, \chi^{2}$ test; ${ }^{\star \star} P<0.01, \chi^{2}$ test.

\section{Discussion}

There are a wide variation and high levels of unmet need for treatment of substance misuse, daytime activities, social company, money budgeting and benefits, psychological distress and physical health in this study. These findings are consistent with rates observed on the receipt of needed services during addiction treatments, as reported in previous research. ${ }^{8,9,11}$ Contrary to the results of previous studies, basic needs (accommodation, food, telephone access, self-care) were generally met. Similar to the results of previous studies, areas that facilitate engagement in treatment (e.g. childcare, transportation) were met. The findings reported in the present study lend support to arguments that providing ancillary supports for addictionrelated psychosocial problems is critical to treatment retention. ${ }^{8}$ A major goal of addiction treatment is to improve quality of life. Patient-rated unmet needs relate to poor quality of life; ${ }^{2}$ therefore, using patient-rated needs as a way of targeting service provision should provide a guide to improving the quality of addiction care treatment.

Ongoing polysubstance use was common in the study sample. Cannabis and heroin use in the past month far exceeded $50 \%$ for both benzodiazepine users and non-users. About $49 \%$ of the respondents reported use of nonprescribed benzodiazepines in the past month. As reported by Manthey and colleagues, these benzodiazepine users are

Table 3 Coefficients in multivariate linear regression predicting severity of needs

\begin{tabular}{|c|c|c|c|c|c|c|}
\hline \multirow{2}{*}{$\begin{array}{l}\text { Substance used } \\
\text { during past month }\end{array}$} & \multicolumn{3}{|c|}{ Total needs } & \multicolumn{3}{|c|}{ Unmet needs } \\
\hline & Coefficient & $95 \% \mathrm{Cl}$ & $P$ & Coefficient & $95 \% \mathrm{Cl}$ & $P$ \\
\hline Heroin & 0.06 & -0.01 to 0.12 & 0.07 & 0.05 & -0.001 to 0.1 & 0.06 \\
\hline Cocaine & -0.04 & -0.19 to 0.11 & 0.58 & -0.03 & -0.16 to 0.11 & 0.69 \\
\hline Benzodiazepines & 0.07 & 0.01 to 0.13 & 0.02 & 0.07 & 0.02 to 0.12 & 0.008 \\
\hline
\end{tabular}


more likely to be single and to have lower educational attainment, compared with non-users. ${ }^{25}$ These findings probably contribute to the high rating for perceived unmet need of substance misuse treatment observed in the study. Chen and colleagues reported that opioiddependent patients have anxiety problems before entering MMT and have pre-existing anxiety problems before their initiation of opiate use. ${ }^{17}$ They suggested that most MMT programmes fail to address the issues of co-occurring anxiety problems, and MMT triggers the onset or worsening of benzodiazepine misuse. This possibly explains why benzodiazepine misuse has independently predicted increasing severity of needs in our study. Therefore, our findings further highlight that MMT services need to focus on and re-evaluate the present treatments for benzodiazepine misuse or dependency, because benzodiazepine misuse or dependency affects MMT outcomes.

\section{Strengths and limitations}

The study has several strengths. First, to the best of our knowledge, no study has previously used the CAN in assessing unmet needs in addiction treatment care. Second, this study describes a representative group of opioid users in the oldest and largest MMT programme in Ireland, during a defined period of standard clinical practice. Third, by using a patient-friendly version of CAN and not relying on the ratings of service providers, the data collected are more likely to reflect patients' actual perceptions and facilitate comparison with similar patient groups elsewhere.

The study is not without limitations. Although the study sample may be representative of opioid dependent users, generalisability of the study findings should be applied in the context of its modest response rate of $56 \%$. Therefore, it is essential to replicate the study's findings in other MMT populations. Information regarding the level of engagement with psychosocial interventions and external supports offered to the respondents was not collected. Opioid-dependent patients are known to have low levels of motivation for engaging satisfactorily with non-pharmacological treatment approaches. ${ }^{26}$ Furthermore, coexisting anxiety disorders are common among opioid-dependent patients, particularly patients who use benzodiazepines. ${ }^{17}$ Data on anxiety and other psychopathology would be interesting, but such data were beyond the scope of the present study. Finally, the results are from an Irish urban population, and levels of available service and support may vary in other settings with different cultural, treatment and socioeconomic characteristics.

\section{Implications for service development}

We identified high levels of unmet needs, particularly for treatment of substance misuse and daytime activities. Assessing literacy skills during substance misuse treatments may increase self-esteem, increase individual autonomy and lead to better employment prospects, thereby satisfying the unmet need for daytime activities. Further, we found evidence to support our suggestion that benzodiazepine misuse by patients on MMT predicts severity of unmet need. Of note, this study focuses on assessing need and does not propose that fulfilling unmet needs will necessarily alter benzodiazepine misuse among opioid users. Future studies investigating the impact of addressing unmet needs and benzodiazepine misuse in MMT are desirable.

\section{Conclusions}

We recommend formal and active assessments of the needs of patients on MMT to help offer the necessary information and advice and to facilitate engagement with the appropriate psychosocial services. Interventions aimed at targeting rapid access to evidence-based treatment approaches for benzodiazepine misuse and dependence are essential.

\section{About the authors}

Tunde Apantaku-Olajide is a consultant general psychiatrist at Saint John Regional Hospital, New Brunswick, Canada. He also holds an academic position in the Department of Psychiatry, Dalhousie University (Dalhousie Medical New Brunswick), Canada. Kevin Ducray is a senior clinical psychologist at the Drug Treatment Centre Board in Dublin, Ireland. Patricia Byrne is a consultant child and adolescent psychiatrist working within Linndara Child and Adolescent Mental Health Service and the Children's University Hospital Dublin, Ireland. She also works as a clinical lecturer with Trinity College Dublin. Bobby P. Smyth is a consultant child and adolescent psychiatrist at the Drug Treatment Centre Board, Dublin, Ireland. He also holds an academic position at the Department of Public Health, Trinity College University Dublin.

\section{References}

1 Salvi $G$, Leese $M$, Slade $M$. Routine use of mental health outcome assessments: choosing the measure. Br J Psychiatry 2005; 186: 146-52.

2 Slade M, Leese M, Cahill S, Thornicroft G, Kuipers E. Patient-rated mental health needs and quality of life improvement. $\mathrm{Br} J$ Psychiatry 2005; 187: 256-61.

3 Wennström E, Sörbom D, Wiesel FA. Factor structure in the Camberwell Assessment of Need. Br J Psychiatry 2004; 185: 505-10.

4 Baksheev GN, Thomas SDM, Ogloff JRP. Psychiatric disorders and unmet needs in Australian police cells. Aust N Z J Psychiatry 2010; 44: 1043-51.

5 Newton-Howes G, Tyrer P, Weaver T. Social functioning of patients with personality disorder in secondary care. Psychiatr Serv 2008; 59: 1033-7.

6 Hansson J, Øvretveit J, Askerstam M, Gustafsson C, Brommels M. Coordination in networks for improved mental health service. Int J Integr Care 2010; 10

7 Van Vugt MD, Kroon $H$, Delespaul PA, Dreef FG, Nugter A Roosenschoon BJ, et al. Assertive community treatment in the Netherlands: outcome and model fidelity. Can J Psychiatry 2011; 56: 154-60.

8 Pringle JL, Emptage NP, Hubbard RL. Unmet needs for comprehensive services in outpatient addiction treatment. J Subst Abuse Treat 2006; 30: 183-9.

9 Joe GW, Simpson DD, Hubbard RL. Unmet service needs in methadone maintenance. Subst Use Misuse 1991; 26: 1-22.

10 Joe GW, Simpson DD, Sells SB. Treatment process and relapse to opioid use during methadone maintenance. Am J Drug Alcohol Abuse 1994; 20: 173-97.

11 Etheridge RM, Craddock SG, Dunteman GH, Hubbard RL, Treatment services in two national studies of community-based drug abuse treatment programs. J Subst Abuse 1995; 7: 9-26. 
12 Asche SE, Harrison PA. The relationship between problem severity and ancillary treatment services: is substance abuse treatment responsive to client need? J Behav Health Serv Res 2002; 29: 345-56.

13 Kumar MR, Rajwal M. Survey of client satisfaction with methadone maintenance programmes. Psychiatr Bull 2006; 30: 16-18.

14 Lintzeris N, Nielsen S. Benzodiazepines, methadone and buprenorphine: interactions and clinical management. Am J Addict 2010; 19: 59-72.

15 Darke S, Swift W, Hall W, Ross M. Drug use, HIV risk-taking and psychosocial correlates of benzodiazepine use among methadone maintenance clients. Drug Alcohol Depend 1993; 34: 67-70.

16 Brands B, Blake J, Marsh DC, Sproule B, Jeyapalan R, Li S. The impact of benzodiazepine use on methadone maintenance treatment outcomes. J Addict Dis 2008; 27: 37-48.

17 Chen K, Berger C, Forde D, D'Adamo C, Weintraub E, Gandhi D Benzodiazepine use and misuse among patients in a methadone program. BMC Psychiatry 2011; 11: 90.

18 Kamal F, Flavin S, Campbell F, Behan C, Fagan J, Smyth R. Factors affecting the outcome of methadone maintenance treatment in opiate dependence. Ir Med J 2007; 100: 393-7.

19 Maremmani I, Shinderman M. Alcohol, benzodiazepines and other drugs use in heroin addicts treated with methadone: polyabuse or undermedication. Heroin Add Rel Clin Probl 1999; 1: 7-13.
20 Fatséas M, Lavie E, Denis C, Auriacombe M. Self-perceived motivation for benzodiazepine use and behavior related to benzodiazepine use among opiate-dependent patients. J Subst Abuse Treat 2009; 37: 407-11.

21 Trauer T, Tobias G, Slade M. Development and evaluation of a patientrated version of the Camberwell Assessment of Need Short Appraisal Schedule (CANSAS-P). Community Ment Health J 2008; 44: 113-24.

22 Slade M, Leese M, Taylor R, Thornicroft G. The association between needs and quality of life in an epidemiologically representative sample of people with psychosis. Acta Psychiatr Scand 1999; 100: 149-57.

23 Slade M, Phelan M, Thornicroft G, Parkman S. The Camberwel Assessment of Need (CAN): comparison of assessments by staff and patients of the needs of the severely mentally ill. Soc Psychiatry Psychiatr Epidemiol 1996; 31: 109-13.

24 Boardman AP, Hodgson RE, Lewis M, Allen K. North Staffordshire Community Beds Study: Iongitudinal evaluation of psychiatric in-patient units attached to community mental health centres. I: Methods, outcome and patient satisfaction. Br J Psychiatry 1999; 175: 70-8.

25 Manthey L, Van Veen T, Giltay EJ, Stoop JE, Neven AK, Penninx BWJH, et al. Correlates of (inappropriate) benzodiazepine use: the Netherlands Study of Depression and Anxiety (NESDA). Br J Clin Pharmacol 2011; 71: $263-72$

26 Seivewright N, Donmall M, Daly C. Benzodiazepines in the illicit drugs scene: the UK picture and some treatment dilemmas. Int J Drug Policy 1993; 4: 42-8. 